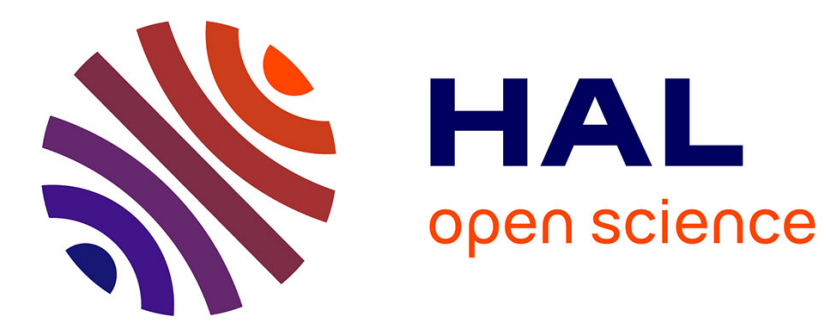

\title{
Modified platinum electrodes: electrochemical characteristics and behaviour in activated sludge
}

Alain Héduit, Isabelle Quinio, Daniel Stadmuller, Daniel R. Thévenot

\section{To cite this version:}

Alain Héduit, Isabelle Quinio, Daniel Stadmuller, Daniel R. Thévenot. Modified platinum electrodes: electrochemical characteristics and behaviour in activated sludge. Water Science and Technology, 1996, 34 (3 - 4), pp.143 - 150. 10.1016/0273-1223(96)00566-5 . hal-01179967

\section{HAL Id: hal-01179967 \\ https://hal.science/hal-01179967}

Submitted on 23 Jul 2015

HAL is a multi-disciplinary open access archive for the deposit and dissemination of scientific research documents, whether they are published or not. The documents may come from teaching and research institutions in France or abroad, or from public or private research centers.
L'archive ouverte pluridisciplinaire HAL, est destinée au dépôt et à la diffusion de documents scientifiques de niveau recherche, publiés ou non, émanant des établissements d'enseignement et de recherche français ou étrangers, des laboratoires publics ou privés. 


\title{
MODIFIED PLATINUM ELECTRODES: ELECTROCHEMICAL CHARACTERISTICS AND BEHAVIOUR IN ACTIVATED SLUDGE
}

\author{
Alain Héduit*, Isabelle Quinio*, Daniel Stadmuller* and \\ Daniel R. Thévenot**
} *Institute of agricultural and environmental engineering research (Cemagref),
Division Qualité des Eaux, 14, avenue de Saint-Mandé, 75012 Paris, France
** University of Paris XII - Val de Marne, Faculty of Science and Technology,
Laboratoire de Bioélectrochimie et Analyse du Milieu (LABAM), 61, Avenue du
Général de Gaulle, 94010 Créteil Cedex, France.

\begin{abstract}
Polished platinum electrodes were coated with platinum black and/or with organic polymers (Nafion, polyurethane) to accelerate the electron tranfer rate to the metal-solution interface and/or to constitute a protection barrier for the metal against neutral or anionic contaminants present in wastewater. The modified electrodes were electrochemically characterized (surface roughness and exchange current density) and their behaviour in activated sludge was studied. A platinum black deposit increases the roughness and the exchange current density. However, the response of these electrodes in an anoxic environment is very slow, which results in a low variation amplitude of the potential when they are placed in activated sludge alternately submitted to sequences of aeration and anoxia. A Nafion film provides partial protection against contaminants thus increasing electrode response reproducibility. A polyurethane film has no apparent protective effect. Copyright $\odot 1996$ IAWQ. Published by Elsevier Science Ltd.
\end{abstract}

\section{KEYWORDS}

Oxidation-reduction potential; activated sludge; platinum black; Nafion; polyurethane; platinum electrode.

\section{INTRODUCTION}

Platinum electrodes have proved to be usable for real time monitoring of the nitrification and denitrification processes in activated sludge treatment plants (De la Menardière et al 1991; Wareham et al, 1994). The use of these sensors, which provide overall information on the redox state of the biological culture, remains difficult owing to the slow electron exchange rates at the interface (Héduit and Thévenot, 1993) and adsorption of contaminants on the platinum surface (Héduit and Thévenot, 1992).

The objective of this work was to estimate the effect of an increase in the electron transfer rate by electrolytic deposition of platinum black, and the feasability of protecting the platinum surface against contaminants by deposition of an organic film; two organic polymers were used : polyurethane (Bindra et al, 
1991), which segregates species according to their size, and Nafion (Harrison et al, 1988), a negatively charged membrane which discriminates between species on the basis of their size and their charge.

The electrochemical characteristics and behaviour in activated sludge of the modified electrodes were investigated.

\section{MATERIAL AND METHODS}

\section{Preparation of the modified platinum electrodes}

The mineral and/or organic deposits were produced using ring electrodes (Ingold Pt 805 ; [area $=0.56 \mathrm{~cm}^{2}$ ] or Inforlab Chimie T13-SC; $\left[\right.$ area $\left.=0.75 \mathrm{~cm}^{2}\right]$ ), after polishing the metal with abrasive strips (grain size 3 and $0.3 \mu \mathrm{m}$ ) fastened to plastic sheets (Tacussel BSC3 and BA03).

Platinum black was deposited by electrolysis in a solution containing $10 \mathrm{ml}$ of hexachloroplatinic acid (Merck), $30 \mathrm{ml}$ of distilled water and $35 \mathrm{mg}$ of lead acetate (Merck Suprapur). Electrolysis lasted $2.5 \mathrm{~min}$ under a current density of $0.5 \mathrm{~mA} / \mathrm{mm}^{2}$. After deposit, the electrodes were left in the same assembly as cathodes for 2.5 minutes in $\mathrm{H}_{2} \mathrm{SO}_{4} 1 \mathrm{M}$ (Prolabo Rectapur), with release of hydrogen.

The polyurethane deposit was obtained by immersion of the electrodes in a 5\% polyurethane solution (Enka SG $85 \mathrm{~A}$ ). This solution (5g of polyurethane in $93.1 \mathrm{~g}$ of tetrahydrofuran and $1.9 \mathrm{~g}$ of dimethylformamide (Prolabo Normapur, i.e. a $98: 2$ mixture) was first shaken for 72 hours to dissolve the polyurethane completely. The electrodes were then dipped into the solution at the level of the sensitive part for 10 seconds. After 10 minutes of open-air drying, the deposit was reinforced by a further ten-second immersion. The electrodes were then left in the open air for one hour, then finally placed for 72 hours in distilled water.

The Nafion deposit was obtained from a commercial solution (5\% Aldrich Chemical) prepared in a wateralcohol solvent. Before the Nafion deposit, the electrodes were dipped into a 5\% trimethylammonium chloride solution (Aldrich Chemical), prepared in anhydrous methanol (Carlo Erba Rpe-Acs), for 1 minute. They were then dried for 20 minutes in the open air, and rinsed in distilled water for a further 20 minutes. The Nafion deposit was obtained by immersion of the electrodes in the solution for 10 seconds. After 1 minute of drying, they were immersed a second time for 10 seconds. The electrodes were then left for 1 hour in the open air at room temperature, then placed for 1 hour in the oven at $105^{\circ} \mathrm{C}$.

Following these surface treatment procedures, the electrodes were left in an aerated reference solution for 24 hours before being characterized. This reference solution was a phosphate buffer saline (PBS) solution ( $\mathrm{pH}$ 6.9) containing $555 \mathrm{ml}$ of $9.07 \mathrm{~g} / 1 \mathrm{KH}_{2} \mathrm{PO}_{4}$ (Prolabo Normapur) and $945 \mathrm{ml}$ of $11.87 \mathrm{~g} / 1 \mathrm{Na}_{2} \mathrm{HPO}_{4}$ (Merck analytical grade) in distilled water with addition of $1 \mathrm{mM} \mathrm{NH}_{4} \mathrm{NO}_{3}$ (Prolabo normapur).

\section{Characterization of the electrodes}

The electrodes were examined before and after their immersion in activated sludge taken from the pilot that had been left in anaerobiosis (polished platinum electrode potential $<-200 \mathrm{mV} / \mathrm{Ag}$. $\mathrm{AgCl}$ ). The following aspects were looked at during this examination :

electrochemical surface characteristics (roughness, charge balance)

electron transfer rate (exchange current density)

zero-current potential in the aerated PBS reference solution

Furthermore, zero-current potentials taken by these electrodes in anaerobic sludge and in activated sludge alternately submitted to aerobic/anoxic (absence of dissolved oxygen / polished platinum electrode potential >- $200 \mathrm{mV} / \mathrm{Ag} . \mathrm{AgCl}$ ) sequences were also examined. 
1. The surface electrochemical characteristics (roughness and charge balance) were determined by triangular sweep cyclic voltammetry in $0.1 \mathrm{M}$ sulfuric acid (Prolabo Normapur) (Ross, 1981; Clavillier et al., 1980; Armand and Clavillier, 1987). The active area of the electrode was determined by evaluating the charge of the hydrogen adsorption peaks (average area of cathodic $\mathrm{Hc}_{1}$ and $\mathrm{Hc}_{2}$ and anodic $\mathrm{Ha}_{1}$ and $\mathrm{Ha}_{2}$ peaks: figure 1), comparing it to its reference value, i.e. $220 \mu \mathrm{C} . \mathrm{cm}^{-2}$ (Bard and Faulkner, 1980). The ratio between the active area and the geometric area constitutes the roughness factor ( $\mathrm{r}$ ). This determination was performed after stabilisation of the I $v s$ $\mathrm{E}$ curves, i.e after 50 potential scans. The charge balance, $\mathrm{q}_{\mathrm{ox}} / \mathrm{q}_{\text {red }}$ (ratio of the anodic area to the cathodic area) was determined on the first voltammetry curve in $0.1 \mathrm{M}$ sulfuric acid. The potential variations $(100 \mathrm{mV} / \mathrm{s})$ were imposed between -250 and $+1150 \mathrm{mV} \mathrm{SCE}$ (Ingold electrode type 303) using a PRT 20-2X type Tacussel potentiostat equipped with a TP-PRT type Tacussel sweep generator.

The I vs E profiles were displayed using a TRP 146 XY SEFRAM type $\mathrm{x}-\mathrm{y}$ recorder. The initial potential was $+600 \mathrm{mV} / \mathrm{SCE}$ (zero current) and the first scan was cathodic.

2. The electron transfer rates (equilibrium exchange current densities $\mathrm{J}^{\circ}$ ) were determined in the PBS reference solution by low potential scan $\left(1 \mathrm{mV} . \mathrm{s}^{-1}\right)$ plotting of the potential-intensity curves (anode and cathode scans around the equilibrium potential and by plotting the Tafel lines $\log |\mathrm{i}|$ vs ( E - E $\mathrm{i}=0$ ), (Héduit and Thévenot, 1989). Potential scans were imposed at $\pm 150 \mathrm{mV}$ around the equilibrium potential using a PRT 20-2X type Tacussel potentiostat coupled with a strip chart recorder (Tacussel EPL2 ).

3. The zero current potentials in the PBS reference solution were measured against a common reference electrode (Ingold Xerolyt, $\mathrm{Ag} . \mathrm{AgCl}$ system, $+210 \mathrm{mV} / \mathrm{NHE}$ at $20^{\circ} \mathrm{C}$ ) using Demca TR 20A high impedance millivoltmeters. The $\mathrm{pH}$ was controlled using a combined Ingold HR 405 type electrode. The measurement of the dissolved oxygen concentration was performed with a Ponselle $\mathrm{O}_{2} \mathrm{P}$ oxymeter. The 21 cell made of transparent PVC was placed in a thermostatted enclosure. It could hold 16 electrodes. The solution was aerated and stirred. The monitoring parameters (pH, $\mathrm{O}_{2}$, potential, temperature) were recorded every 3 seconds by an Aquadiag data acquisition system (Neurotronic), then transferred and processed on a PC microcomputer using an Excel spreadsheet.

4. The zero current potentials in anaerobic sludge and in activated sludge alternately submitted to aerobic/anoxic sequences were monitored using the equipment described above. The pilot plant included an 89-litre aeration basin and a $0.122 \mathrm{~m}^{2}$ parallelepipedic clarifier. A supply, separating the organic load (meat-juice based substrate (Viandox) $+21.3 \mathrm{~g} / 1 \mathrm{NH}_{4} \mathrm{Cl}$, (Prolabo Rectapur)) from the hydraulic load (tap water), was applied. The recycling of sludge from the clarifier (200\% of the input flow) to the aeration basin was synchronized with the input of tap water. The supply figure simulates the hourly variations of the real wastewater treatment plants. The cyclic aeration was provided by a fine-bubble air insufflation system coupled with a mechanical stirrer connected to timers. The load applied was $0.086 \mathrm{~g} \mathrm{BOD/g}$ MVLSS.day.

\section{RESULTS AND DISCUSSION}

\section{Electrochemical surface characteristics}

Starting from $+600 \mathrm{mV} / \mathrm{SCE}$, the potential scan begins in the cathodic direction; the scan direction is reversed at $-250 \mathrm{mV} / \mathrm{SCE}$, and again at $1100 \mathrm{mV} / \mathrm{SCE}$ (figure 1). Progressively the peaks corresponding to proton reduction and hydrogen adsorption $\left(\mathrm{Hc}_{1}\right.$ and $\left.\mathrm{Hc}_{2}\right)$ and desorption $\left(\mathrm{Ha}_{1}\right.$ and $\left.\mathrm{Ha}_{2}\right)$, and the peaks corresponding to surface oxidation or adsorbed oxygen formation (Oa) and surface reduction (Or) are formed and stabilized. 
The stabilized voltammogram obtained with platinum black electrodes (figure 2), i.e. after 50 cyclic potential scans, is different to that obtained with a polished electrode. The peaks corresponding to the hydrogen adsorption and desorption processes are less marked, and the area corresponding to the anodic desorption of hydrogen moves toward more positive values.

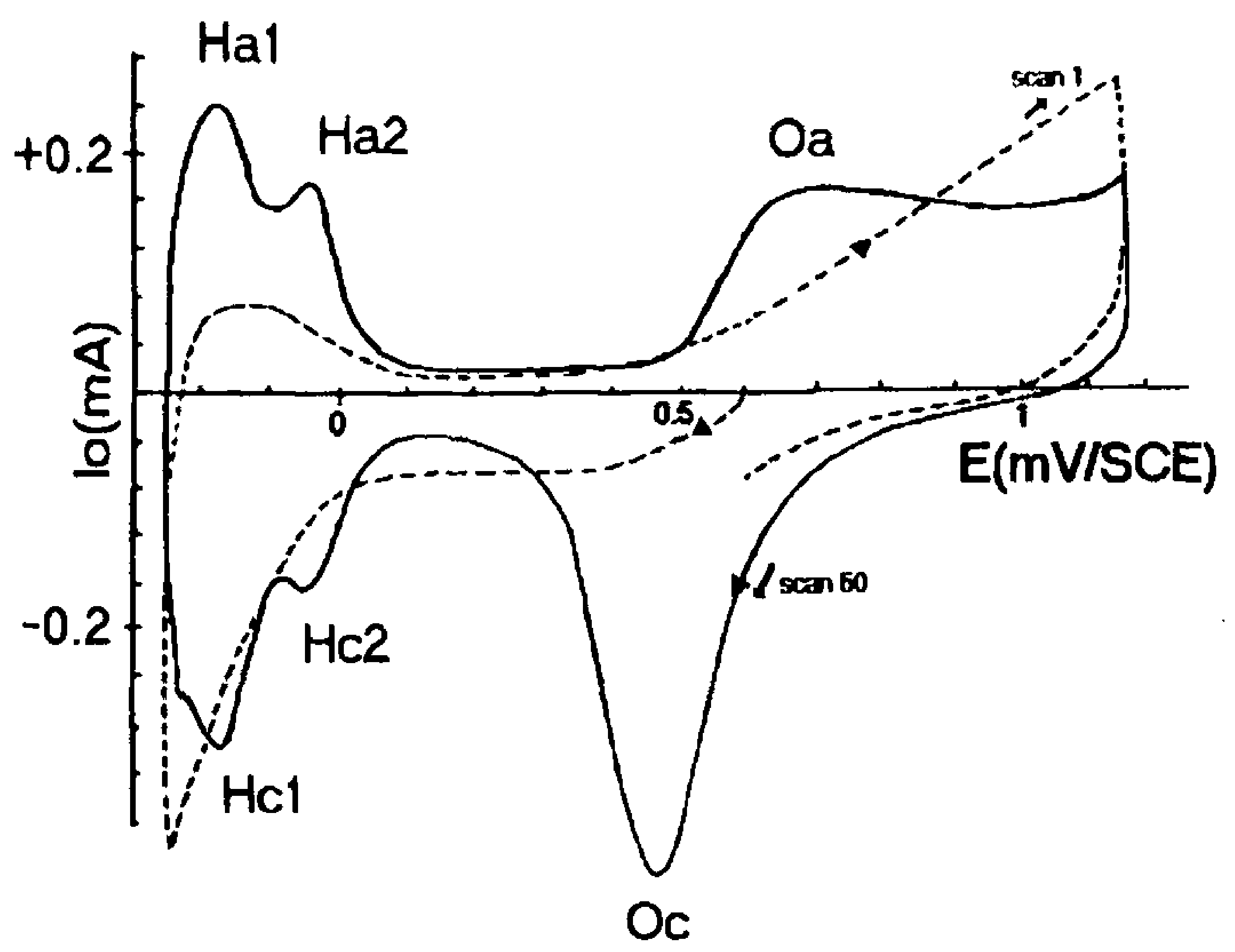

Figure 1. Typical voltammogram of polished Pt electrodes in $0.1 \mathrm{M}$ sulfuric acid after immersion for $24 \mathrm{~h}$ in aerated PBS solution.

Scan $1(\ldots)$ and $50(-)$

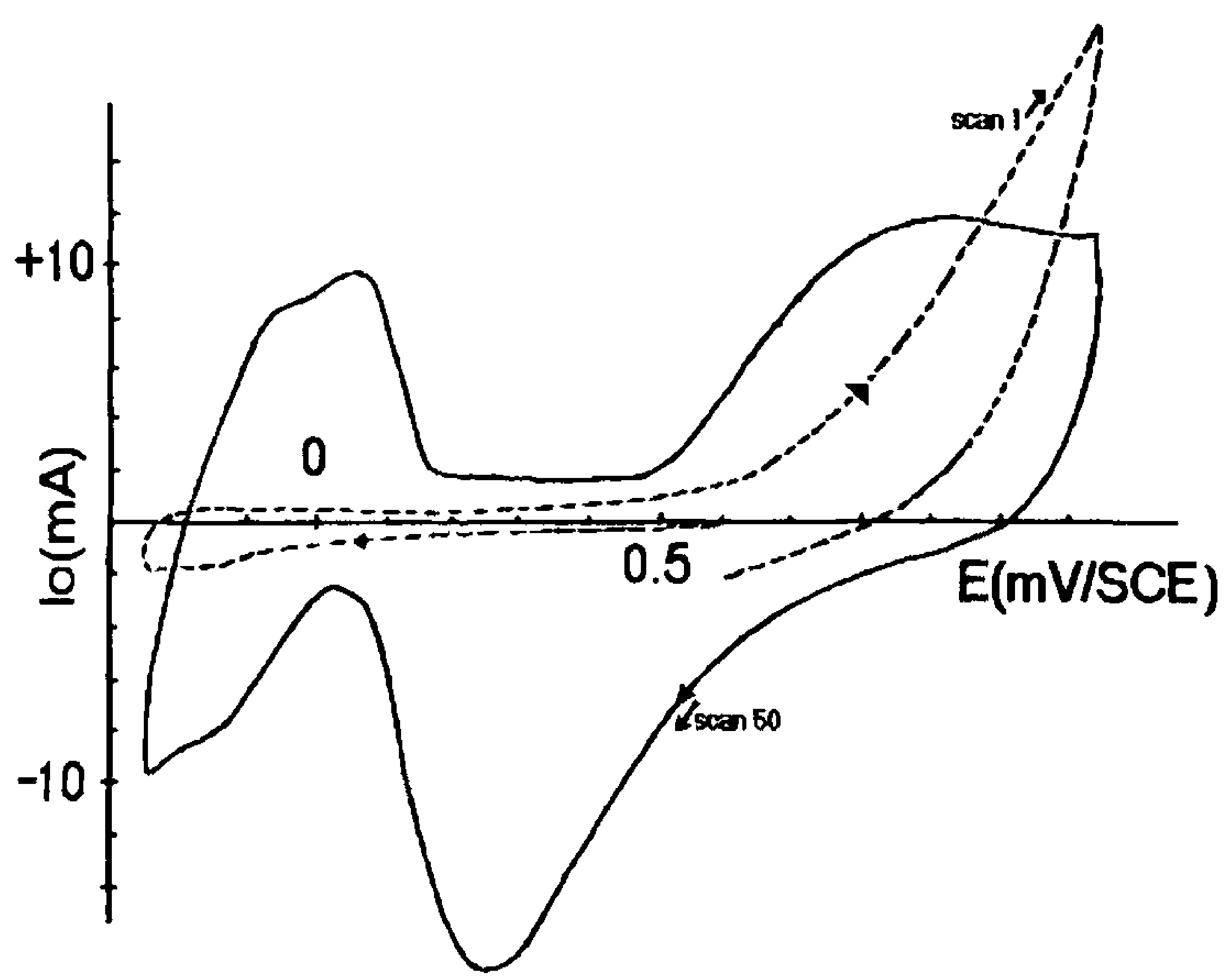

Figure 2. Typical voltammogram of $\mathrm{Pt}$ black electrodes in $0.1 \mathrm{M}$ sulfuric acid after immersion for $24 \mathrm{~h}$ in anaerobic sludge.

Scan $1(\ldots$.$) and 50(-)$

The immersion of Nafion coated electrodes into $\mathrm{H}_{2} \mathrm{SO}_{4} 0.1 \mathrm{M}$ makes the coating fragile, then disbonds it. The polyurethane membranes withstand immersion in acid, but the voltammogram obtained is a straight line which crosses the voltage axis between +0.3 and $+0.4 \mathrm{~V} / \mathrm{SCE}$, thus showing the high ionic resistance of these dense membranes. It was therefore impossible to determine the roughness and the charge balance for both types of coating.

The roughness factors corresponding to the polished electrodes are close to 4 (table 1). For platinum black, the measured factors range between 130 and 220 . This wide range can be explained by the fragile nature of the platinum black deposit. In both cases, the charge balances are close to a unit value before immersion of 
electrodes into the anaerobic sludge. The immersion of electrodes for 24 hours in the anaerobic sludge increases the value of the charge ratio, irrespective of the surface treatment : the values obtained ( 5 to 8.5 ) reveal the adsorption of reduced species on the platinum or on the production of platinum sulfide derivative.

Table 1. Roughness and charge balance factors either ( ) before or [ ] after a 24-hour immersion into anaerobic sludge

\begin{tabular}{|c|c|c|}
\hline & Polished Pt electrode & Pt black electrode \\
\hline Roughness factor $(r)$ & $(4.1-4.2),[3.9-4.2]$ & $(185-220),[130-165]$ \\
Charge balance $\left(\mathrm{q}_{\mathrm{ox}} / \mathrm{q}_{\mathrm{red}}\right)$ & $(1.05-1.2),[5.0-8.5]$ & $(0.95-1.05),[7.8-8.5]$ \\
\hline
\end{tabular}

\section{Exchange current densities}

The exchange current densities corresponding to polished electrodes are in the 0.02-0.04 $\mu \mathrm{A} . \mathrm{cm}^{2}$ range, the lowest values having been obtained after immersion into an anaerobic sludge (table 2). Immediately after polishing, the densities usually lie within a range of higher current densities : 0.1 to $0.2 \mu \mathrm{A} . \mathrm{cm}^{2}$ (Héduit et al, 1993). The exchange current densities corresponding to platinum black electrodes are in the 1.7-3 $\mu \mathrm{A} . \mathrm{cm}^{2}$ range. This high level of electron exchange, linked to the roughness of the deposit, is maintained after the immersion of the electrodes into anaerobic sludge.

The current densities obtained for the electrodes coated with polyurethane are similar to those corresponding to polished electrodes. Nafion seems to have a slightly positive effect on the exchange current density. Coating the platinum black with a Nafion film results in a substantial decrease of the electron transfer rate if one refers to the densities obtained on the platinum prior to immersion in anaerobic sludge. It is nevertheless noteworthy that very high current densities, such as 2.0 to $2.4, \mu \mathrm{A} . \mathrm{cm}^{2}$ are maintained on the platinum black coated with Nafion even after 24 hours in an anaerobic environment.

Table 2. Exchange current density ranges in the PBS reference solution

\begin{tabular}{|c|c|c|}
\hline $\begin{array}{c}\text { Treatment of } \\
\text { Pt } \\
\text { electrode }\end{array}$ & $\begin{array}{c}\mathrm{J}^{\circ} \text { range in the PBS reference } \\
\text { solution before immersion into } \\
\text { anaerobic sludge } \\
\left(\mu \mathrm{A} \cdot \mathrm{cm}^{-2}\right)\end{array}$ & $\begin{array}{c}\mathrm{J}^{\circ} \text { range in the PBS reference } \\
\text { solution after immersion into } \\
\text { anaerobic sludge } \\
\left(\mu \mathrm{A} . \mathrm{cm}^{-2}\right)\end{array}$ \\
\hline Polishing & $0.03-0.04$ & 0.02 \\
Platinum black & $1.7-3$ & $2.1-2.8$ \\
Polyurethane & $0.02-0.03$ & 0.02 \\
Nafion & $0.03-0.06$ & $0.04-0.07$ \\
Platinum black + Nafion & $1.2-1.4$ & $2.0-2.4$ \\
\hline
\end{tabular}

\section{Zero-current potentials in the PBS reference solution before and after immersion into anaerobic sludge}

Prior to immersion in anaerobiosis, the modified electrodes show zero-current potentials 20 to $50 \mathrm{mV}$ higher than those of polished platinum (figure 3). After immersion into anaerobic sludge, when the electrodes are again placed in the same PBS buffer solution, the potential readings are 20 to $190 \mathrm{mV}$ below the original voltage. The smallest variations are observed for the electrodes covered with platinum black and/or with Nafion, thus showing that two strategies could be considered to protect the platinum electrodes from the effects of anaerobic sulfide-rich biological environments : either increased roughness, or anionic membrane coating. 


\section{Zero-current potentials in anaerobic sludge}

The electrode modifications have no significant effect on the electrode potential in a high reducing medium (table 3). The polyurethane deposit seems to reduce the voltage slightly. This shows that, under stationary conditions, the surface treatments of platinum electrodes do not result in any significant modification in their behaviour.

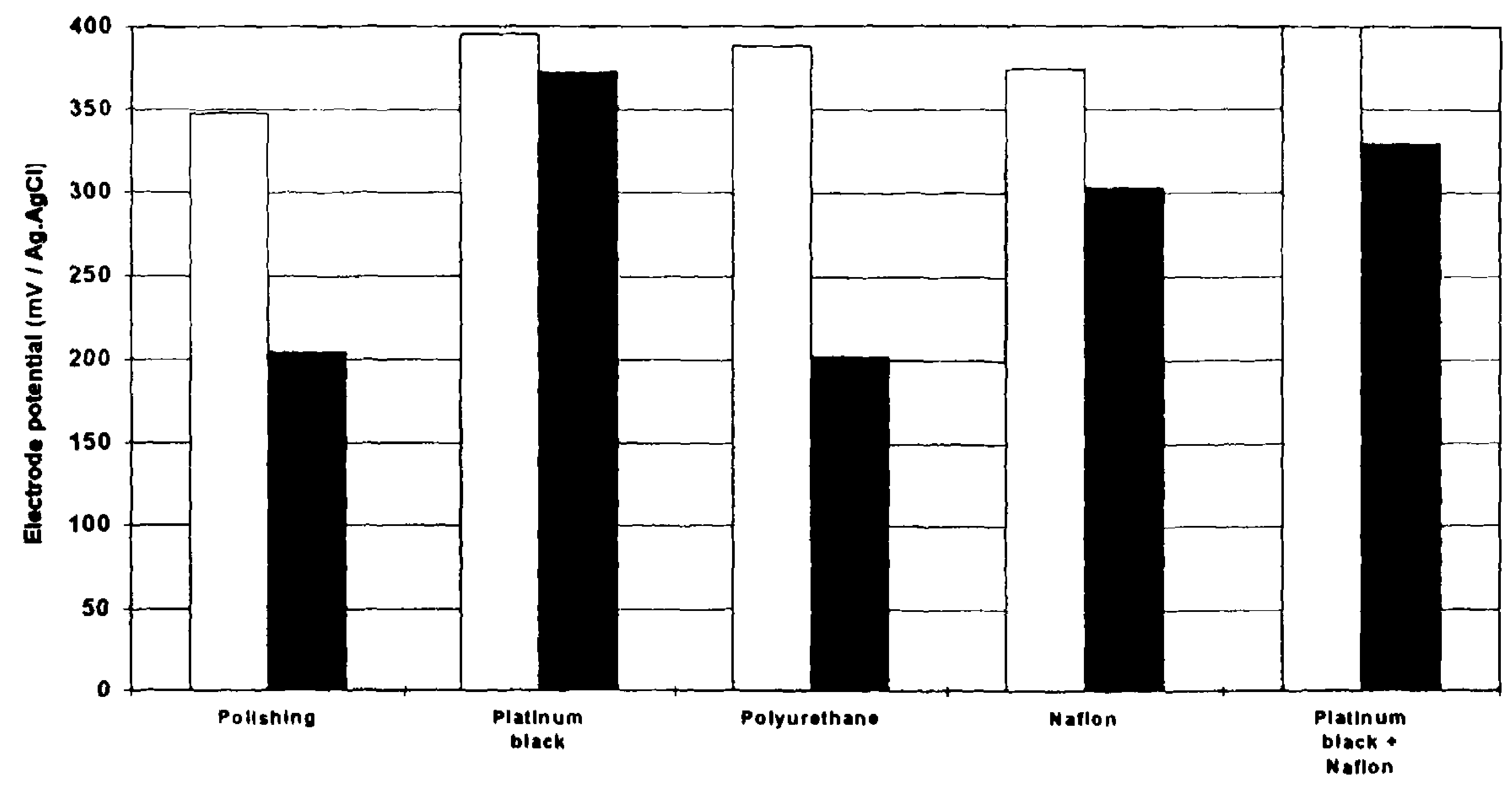

Figure 3. Zero-current potentials of modified electrodes in the PBS reference solution either $\square$ before or $\square$ after a $24 \mathrm{~h}$ immersion into anaerobic sludge.

Table 3. Stabilized zero-current potentials taken by the modified electrodes in anaerobic activated sludge

\begin{tabular}{|c|c|c|}
\hline & $\begin{array}{c}\text { Stabilized } \mathrm{E}_{\mathrm{i}=0} \text { of modified } \\
\text { electrode }(\mathrm{mV} / \mathrm{Ag} . \mathrm{AgCl})\end{array}$ & $\Delta \mathrm{E}_{\mathrm{i}=0}$ modified - polished (mV) \\
\hline Pt black & -552 to -561 & -6 to- 11 \\
Polyurethane & -488 to -498 & -54 to- 64 \\
Nafion & -550 to -555 & -4 to- 9 \\
Pt black + Nafion & -498 to -508 & -4 to- 16 \\
\hline
\end{tabular}

\section{Zero current potentials in activated sludge, alternately submitted to aerobic and anoxic sequences}

During the aeration periods, the electrode potentials increase. They decrease as the dissolved oxygen concentration decreases after aeration stops. Compared to polished platinum electrodes, the platinum black electrodes show potentials which shift towards positive values and present a significantly lower variation amplitude (figure 4). Considering the results shown in Table 3, this low amplitude variation can be explained by the slow stabilization rate of electrodes coated with platinum black during the anoxic period. This slowness could be due to the presence of platinum oxides such as $\mathrm{PtO}$ on the surface of the electrolytically deposited $\mathrm{Pt}$ grains, since these grains constitute an oxidizing reserve with high catalyst activity.

Under sequentially aerated conditions, the behaviour of a electrode coated with polyurethane is similar to that of an platinum black electrode (figure 5) : more positive potentials than for polished platinum and a lower variation amplitude. However, a clear break can be seen in the potential evolution during its decreasing phases. This is not observed with platinum black. The Nafion coated electrode initially evidences a potential variation close to that of the polished electrode with a $50-70 \mathrm{mV}$ shift towards more positive values. This variation seems to be dampened after a few days' aeration/anoxia cycles. 


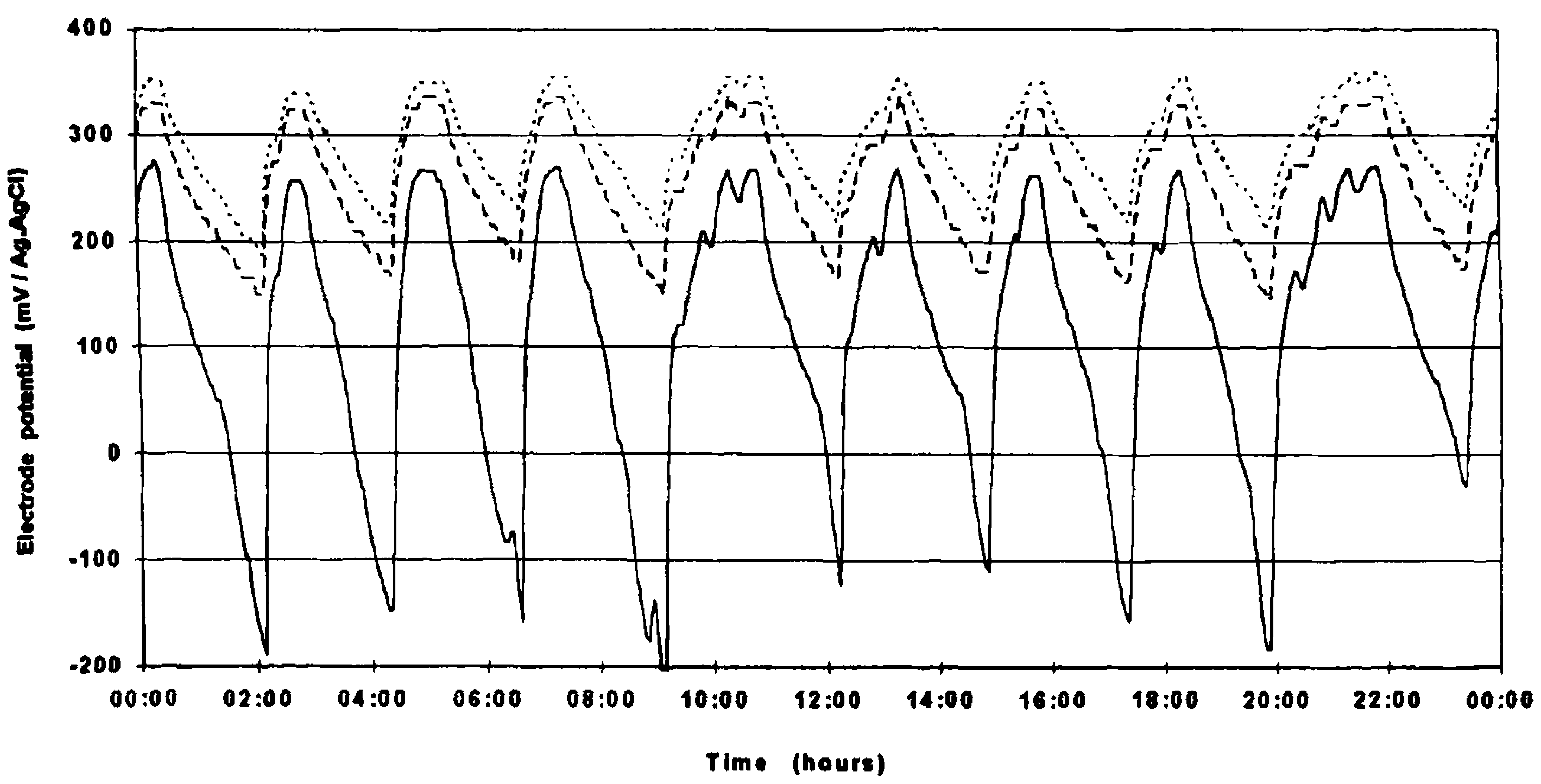

Figure 4. Comparative evolution of the potentials taken by (-) polished electrodes, (---) platinum black electrodes and (...) electrodes coated with platinum black and a Nafion film in sequentially aerated activated sludge.

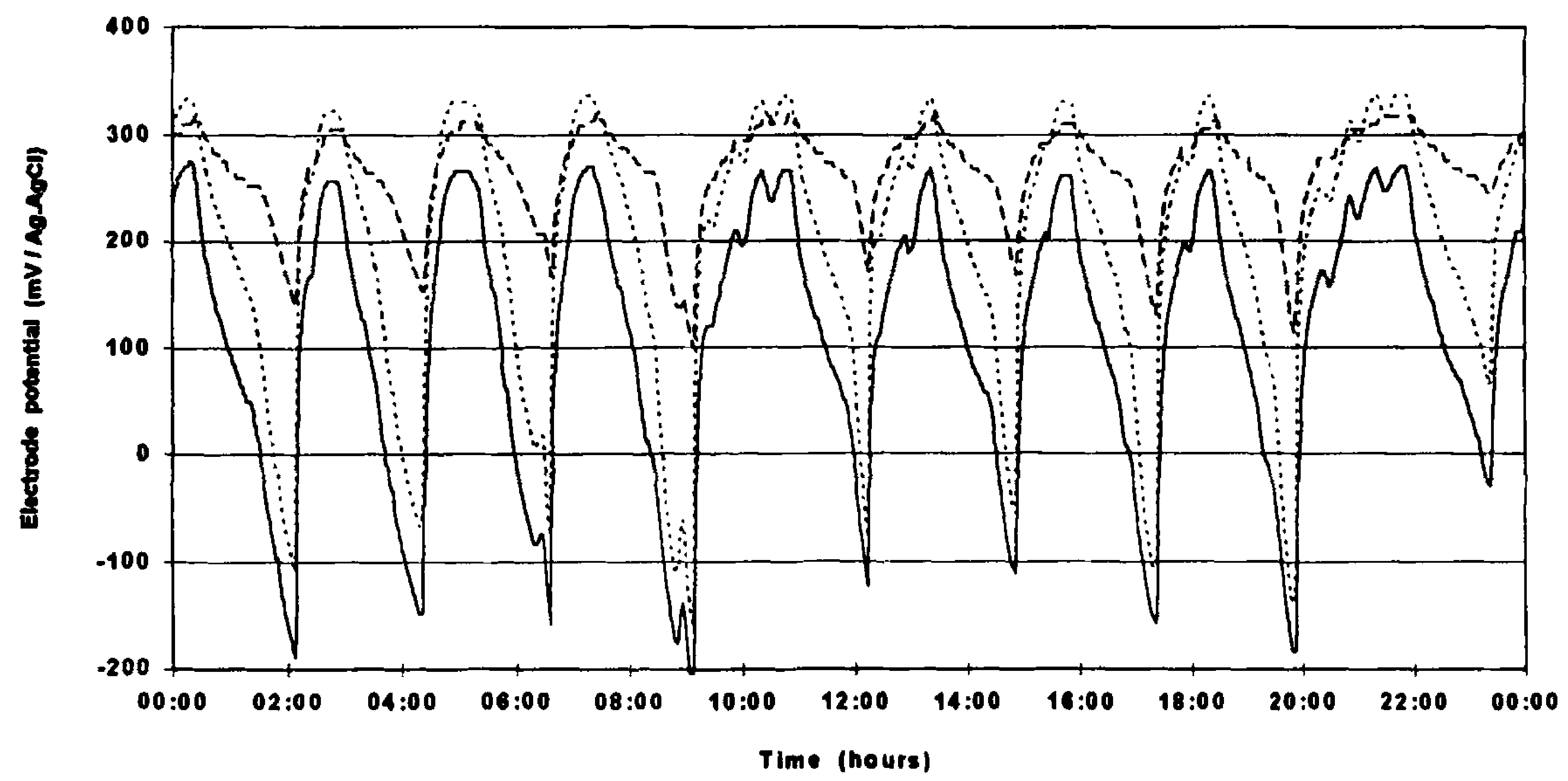

Figure 5. Comparative evolution of the potentials taken by $(-)$ polished electrodes and electrodes coated with (...) a Nafion or (---) a polyurethane film in sequentially aerated activated sludge.

\section{CONCLUSION}

As expected, the electrolytic deposit of platinum black considerably increases the roughness factor of a platinum electrode, the ratio between the active surface and the geometric surface being in the order of 130 to 220 , resulting in high exchange current densities $\left(2-3 \mu \mathrm{A} . \mathrm{cm}^{2}\right)$ which are maintened after a 24-hour immersion in anaerobic sludge. In such a medium, these electrodes present stabilized potentials similar to those of polished electrodes. When maintained in anaerobiosis such platinum black surfaces present a change in the surface state resulting from the adsorption or reaction of species: the anodic/cathodic charge ratio in sulfuric acid increases from 1 to 8 . Nevertheless, this situation does not bring about any substantial drift in the potential of the platinum electrode when it is returned to an aerated medium, contrary to the simply polished electrode. However, these platinum black coated electrodes show very slow variation rates when placed in an aerated environment which becomes anoxic. This results in a low potential variation 
amplitude when they are placed in sludge which is alternately submitted to sequences of aeration and absence of aeration necessary for nitrification and denitrification. This phenomenon may be due to the presence of oxides which form an oxidizing reserve on the surface and therefore slow down the evolution of the potential towards negative drift. This hypothesis appears to be supported by the high potentials noted in the aerated PBS reference solution and by the low potential drift following an immersion into an anaerobic medium, since the oxides form a protective layer which initially reacts with the reducing compounds. Owing to these slow kinetics, such platinum black coated electrodes do not appear to present any potential interest for aeration basin control. Moreover, the fragile platinum black deposit can be damaged by simple friction.

The Nafion film deposited on the polished platinum slows down the contamination of the electrode by reducing agents, since the response drift caused by immersion into an anaerobic medium is lower than for polished platinum. Moreover, the mechanical resistance of the Nafion deposit is good. A Nafion-covered electrode placed in an aeration basin sequentially submitted to aeration and anoxia sequences will initially show a potential variation close to that of a polished electrode. This variation may be dampened following a few days aeration/anoxia cycles.

The deposit of a Nafion film on a platinum black layer has little effect on the characteristics and behaviour of the electrode, but has the advantage of fixing and protecting the platinum black. This type of electrode could be interesting for monitoring anaerobic zones in biological phosphorus removal plants owing to the high electron transfer rates noted.

Finally, the polyurethane deposit, which offers a good mechanical resistance on the platinum, does not constitute an efficient barrier against anaerobic contaminants. It gives the electrode a low reactive rate and seems to modify the behaviour of the platinum electrode in anaerobiosis.

\section{ACKNOWLEDGEMENTS}

The present work was supported by grant no. EV5V-CT93-0245 from the EEC Environment Program

\section{REFERENCES}

Armand, D. and Clavillier, J. (1987). Quantitative analysis of the distribution of the hydrogen adsorption states at platinum surfaces: application to $\mathrm{Pt}\{100\}$ in sulfuric acid medium. J. Electroanal. Chem. 225, 205-214.

Bard, A. J. and Faulkner, L. R. (Ed.) (1980). Electrochemical methods. John Wiley and Sons.

Bindra, D. S., Zhang, Y., Wilson, G. S., Sternberg, R., Thevenot, D. R., Moatti, D. and Reach, G (1991). Design and in vitro studies of a needle type glucose sensor for subcutaneous monitoring. Anal. Chem. 63, 1692-1696.

Clavillier, J., Armand, D. and Wu, B. L. (1980). Electrochemical study of the initial conditions of platinum surfaces with \{100\} and $\{110\}$ planes. J. Electroanal. Chem. 135, 159-166.

De la Ménardiere, M., Charpentier, J., Vachon, A. and Martin, G. (1991). ORP as a control parameter in a single sludge biological nitrogen and phosphorus removal activated sludge system. Water SA. 17, 123-132.

Harisson, J., Turner, F. B. and Baltes, H. P. (1988). Characterization of perfluorosulfonic acid polymer coated enzyme electrodes and a miniaturized integrated potentiostat for glucose analysis in whole blood. Anal. Chem. 60, 2002-2007.

Héduit, A. and Thévenot, D. R. (1989). Relation between redox potentials and oxygen levels in activated sludge reactors Wat. Sci. Tech. 21(8/9), 947-956.

Héduit, A. and Thévenot, D. R. (1992). Elements of interpretation of platinum electrode potentials in biological treatment. Wat. Sci. Tech. 26(5/6), 1335-1344.

Héduit, A., Martin, B., Duchamp, I. and Thévenot, D. R. (1993). Comparison of gold and platinum electrode responses in activated sludge. Wat. Sci. Tech. 28(11/12), 473-480.

Ross, P. N. (1981). Hydrogen chemisorption on Pt single crystal in acidic solutions. Surface Science, 102, 463-485

Wareham, D. G., Mavinic, D. S. and Hall, K. J. (1994). Sludge digestion using ORP-regulated aerobic-anoxic cycles. Wat. Res., 28, 373-384. 